\title{
Registros e memória: algumas observações sobre a demografia brasileira no contexto latino-americano
}

\author{
Maria Coleta Ferreira Albino de Oliveira* \\ Ricardo Antônio Wanderley Tavares**
}

\begin{abstract}
Trata-se de uma reflexão, 30 anos depois, sobre o que significou o fervilhante período dos anos 70 na demografia do Brasil e da América Latina. Seguindo um estilo de autocrítica e celebração, são utilizados registros escritos e da memória do que foi, naquele momento, um projeto coletivo, científico e político na região. $O$ artigo leva em conta o contexto social, político e econômico do período, as características das lideranças na disciplina à época, o estilo de financiamento internacional de grupos e instituições e o caráter crítico da prática científica na demografia daquele período. Como avaliação crítica da trajetória intelectual de um grupo, os autores reconhecem que o processo analisado comporta outras visões e apreciações. Referências bibliográficas são incluídas com a finalidade de documentar alguns registros e oferecer um roteiro àqueles que desejarem enveredar por conta própria pelo período.
\end{abstract}

Palavras-chave: Demografia brasileira. Demografia na América Latina. Estudos de fecundidade. História da demografia.

A oportunidade oferecida pela iniciativa da Rebep, na figura de Elisabete Bilac, de preparar um volume especial da revista dedicado a uma reflexão sobre a constituição do campo da demografia no Brasil abre a possibilidade de refletir, 30 anos depois, sobre o que significou o fervilhante período dos anos 70 no Brasil e na América Latina. Registros escritos e da memória nos conduzirão por um espinhoso caminho de autocrítica e, contraditoriamente, de celebração. Ao percorrê-lo, temos plena consciência de que as reflexões que se seguem não farão certamente justiça às contribuições e ao papel desempenhado por várias das figuras que participaram do que foi, naquele momento, um projeto coletivo, científico e político, com todos os ônus e bônus da empreitada.
Duas outras razões - afora a insistência de Bete Bilac e de George Martine - nos estimularam a escrever estas notas. Desde logo é preciso dizer que os leitores sentirão certamente falta de um tom mais acadêmico, encontrando o que talvez se pareça a uma crônica. Crônica da trajetória intelectual de um grupo, que comporta outras visões e apreciações. Referências bibliográficas serão incluídas com a finalidade de documentar alguns registros e oferecer um roteiro àqueles que desejarem enveredar por conta própria pelo período.

A primeira razão tem a ver com a recente criação da Associação Latino-Americana de População (Alap), que, para muitos de nós, marca uma nova etapa da discussão e da colaboração técnico-acadêmica em

\footnotetext{
*Cientista Social, professora do Departamento de Demografia e Pesquisadora do Nepo, ambos da Unicamp.

${ }^{* *}$ Economista e Cientista Social, Centro de Pesquisa Aggeu Magalhaes (CPqAM), Fiocruz Recife.
} 
temas de população na região. A segunda liga-se a uma rápida conversa de um dos autores deste texto com um demógrafo norte-americano, por ocasião da recente reunião da Population Association of America, na Filadélfia. Indagava este colega sobre referências bibliográficas que the pudessem ser eventualmente recomendadas sobre as formulações que a uma certa época se desenvolveram na América Latina sobre a noção de "estratégias de sobrevivência" na discussão sobre a fecundidade na região. A par da agradável surpresa, a sensação foi a de que os anos 70 não haviam terminado e que, talvez, ficáramos devendo um desenlace.

O final dos anos 60 e a década de 70 foram um período de intenso debate intelectual e político entre cientistas sociais da América Latina. Como já chamaram a atenção inúmeros autores, a falência das estratégias de desenvolvimento em responder adequadamente aos desafios das sociedades latino-americanas, a aparente impossibilidade de superar obstáculos estruturais à mudança, toda esta frustração levou à formulação de duras críticas às pressuposições dos modelos de desenvolvimento econômico e social propostos para o continente.

Os estudos de população em nosso meio foram, desde o começo, liderados em sua maioria por cientistas sociais e intelectuais comprometidos e envolvidos neste debate, a um tempo teórico e político. Por isso, não é surpreendente que desde o começo da constituição do campo da demografia na América Latina estivessem presentes ácidas críticas à idéia de explosão demográfica como o obstáculo por excelência aos objetivos de desenvolvimento. Por isso, apesar de que diversas perspectivas e posições estivessem presentes nos primeiros trabalhos e pesquisas sobre população na região - como veremos adiante -, a demografia como prática científica naquele período esteve profundamente marcada por uma perspectiva crítica.

Por ocasião da Conferência Regional de População realizada no México, em 1970, um grupo de especialistas em população da América Latina reuniu-se e, apoiado grandemente por recursos de agências internacionais e fundações norteamericanas, deslanchou um programa ambicioso de estímulo à pesquisa crítica sobre temas de população na região. Havia neste grupo de pioneiros - e o crescimento do interesse pelo campo mostrou que não estavam sozinhos - uma insatisfação profunda com o receituário político e com as abordagens teóricas incluídos nos pacotes de cooperação internacional. A "bomba populacional" e a "teoria da modernização" foram desacreditadas como idéias-chave para o entendimento das tendências e dos comportamentos demográficos no continente. A crítica a estas idéias foi apoiada em uma perspectiva teórica gerada na região, original se podemos assim afirmar, desenvolvida na tradição do estruturalismo marxista. A assim chamada abordagem histórico-estrutural ganhou crescente prestígio entre os especialistas de população, sob a influência de lideranças intelectuais de peso.

De fato, a demografia na América latina foi durante algum tempo um locus de debate teórico e político, especialmente nas décadas marcadas por regimes políticos autoritários. A pesquisa em temas de população era vista como politicamente neutra pelo establishment autoritário. Isso de um lado. De outro, enquanto recursos para pesquisa eram escassos ou simplesmente inexistiam para quem quisesse se debruçar sobre temas sociais e econômicos politicamente relevantes, a indagação acerca das razões responsáveis pela manutenção da fecundidade em níveis elevados era capaz de mobilizar financiamentos generosos. Algumas conseqüências emanam destas circunstâncias.

Primeiro, as possibilidades de financiamento para a pesquisa demográfica e o ambiente político autoritário combinaramse em provocar a cooptação tanto de cientistas maduros como de estudantes de pós-graduação para o campo da população. Segundo - e relacionada à primeira -, abordagens teóricas e metodologias de pesquisa já em uso em outras áreas das ciências sociais foram incorporadas ao campo dos estudos de população. A combinação de técnicas quantitativas e 
qualitativas, por exemplo, foi uma das características da pesquisa em população no período, especialmente no Brasil, apesar da reação de alguns. Decerto vozes discordantes foram extremamente importantes na constituição do campo, que esteve longe da unanimidade. O que era a tônica dominante, sem dúvida, era o clima de debate, terceira implicação das circunstâncias apontadas.

E este é um dos aspectos que vale a pena destacar: a riqueza teórica e criatividade intelectual propiciadas pelo intenso intercâmbio de idéias e experiências na região. É precisamente este clima de discussão e de colaboração que inspira muitos dos que participaram da criação da Alap, como são testemunho os documentos produzidos nos dois anos que antecederam o I Congresso da Alap, realizado em setembro de 2004 em Caxambu. ${ }^{1}$

Este intercâmbio se deu no contexto de espaços institucionais que foram sendo abertos para estimular a produção de conhecimento e proporcionar oportunidades de debates. Várias instituições localizadas nos diversos países da região tiveram importante papel no período. Para não corrermos o risco de deixar de mencionar, por lapso, alguma que não poderia deixar de ser citada, registramos apenas dois espaços institucionais estratégicos. Do ponto de vista do intercâmbio, adquiriram crescente importância a Comissão de População e Desenvolvimento, criada no âmbito do Conselho Latino-Americano de Ciências Sociais (Clacso), e, em seguida, o Programa de Investigação Social em População na América Latina (Pispal). Ambos promoveram grupos de trabalho, seminários e reuniões e o segundo comandou um programa de financiamento à pesquisa, dentre outros então existentes na região. Muito embora utilizasse recursos internacionais, o Pispal pôde garantir liberdade para a definição de agendas de investigação próprias, regional ou nacionalmente acordadas, produto de uma estratégia hoje - e desde algum tempo abandonada pela maior parte das agências.
Dentre os tópicos de pesquisa, talvez a maior ênfase tenha recaído na fecundidade, embora as migrações internas tenham sido alvo de considerável interesse. Havia uma preocupação com uma redefinição crítica do objeto de estudo, o que acabou por ampliar o escopo dos estudos de fecundidade, para incluir o contexto da reprodução. As ciências sociais, especialmente a sociologia e a antropologia, tiveram importante papel na construção de conceitos, muitas vezes emprestados destas disciplinas, para dar conta da pretendida redefinição crítica à luz de uma perspectiva histórico-estrutural. Conceitos como "reprodução da população", "reprodução social", "reprodução das classes" e outros foram utilizados no esforço de explicar o que era considerado um processo social - e não um fenômeno apenas - extremamente complexo.

A perspectiva crítica que se construía acerca das questões populacionais foi também bastante influenciada pelo diálogo com os estudos sobre a pobreza. Era a época dos estudos sobre a marginalidade social, que influenciaram tanto as pesquisas sobre o comportamento político do operariado, quanto as formulações sobre o comportamento reprodutivo das camadas populares urbanas. A noção de "estratégias de sobrevivência" é incorporada aos estudos de fecundidade neste contexto. Esta noção colocava ênfase na articulação entre escoIhas e constrangimentos na conformação de comportamentos responsáveis por determinados níveis de fecundidade. Contrariamente a formulações posteriores e que vicejaram (e talvez ainda vicejem!) em várias partes do mundo, a assim chamada abordagem histórico-estrutural não desconhecia a importância de fatores e forças ideológicas na determinação do comportamento com relação à reprodução. A maior força do argumento teórico estava na hipótese de que as intenções reprodutivas de diferentes grupos ou segmentos sociais refletiam, em grande medida e de alguma maneira, o modo de inserção de cada qual na sociedade, recusando o etnocentrismo

${ }^{1}$ Os documentos relativos à criação da Alap podem ser encontrados no website da Abep: <www.abep.org.br>. 
envolvido no privilegiamento de mecanismos de difusão e imitação na explicação da mudança cultural.

\section{Fecundidade, reprodução da população, reprodução social}

A centralidade do tema da fecundidade no período faz com que nos detenhamos aqui no que foi o mais importante espaço institucional regional de produção intelectual nesta área temática, a Comissão de População e Desenvolvimento do Clacso, doravante chamada de Comissão. E embora a demografia brasileira estivesse presente de modo significativo em outros campos de pesquisa, neste, sem dúvida, são evidentes os registros da importância de um momento da demografia brasileira relativamente ignorado pelas gerações mais jovens de profissionais da área.

A Comissão foi criada em princípios de 1971 e se estruturou em torno de três Grupos de Trabalho: Informação Sociodemográfica, Migrações e Fecundidade. Em sua primeira reunião, realizada na Cidade do México de 9 a 14 de novembro de 1972, o Grupo de Trabalho sobre Estudos de Fecundidade decidiu mudar seu nome, assumindo denominação que julgava mais consistente com a perspectiva teórica que animava seus integrantes: Grupo de Trabalho sobre o Processo de Reprodução da População. O Prorepop, como veio a ser referido, realizou sete reuniões internacionais, produziu cerca de cem títulos e em torno de 10 mil páginas entre livros, papers e relatórios de pesquisa. Tornou-se, entre sua primeira reunião e a última - realizada em Cuernavaca, México, de 2 a 5 de fevereiro de 1982 -, um dos principais foros de discussão das ciências sociais latinoamericanas.

A mudança de nome é um registro claro da preocupação do grupo com a construção de sua identidade. Já na primeira reunião, seus membros explicitaram que a análise do processo reprodutivo se faria de uma perspectiva histórico-estrutural. Dada esta perspectiva, o objetivo do programa de pesquisa que se visualizava envolveria a consideração da dinâmica da população em seu conjunto, incluindo também os outros dois fatores básicos da equação demográfica: a mortalidade e as migrações. Os registros não deixam claro o que seria exatamente a perspectiva histórico-estrutural, mas certamente tinha a ver, entre outras, com um alinhamento a teorias sociais em desenvolvimento na América Latina, em especial a Teoria da Dependência. Com certeza as pretensões teóricas eram bastante elevadas, como exemplifica trecho do relatório da primeira reunião:

En esta forma se deben de tomar en cuenta aquellas aportaciones teóricas que van desde la consideración de fenómenos que resultan del comportamiento psicosocial de los individuos en la relación sexual hasta aquellos estudios que incluyen el análisis de relaciones supraestructurales asociadas a la ideología, y considerando las propias estructuras económicas, sociales y políticas en que se da el proceso reproductivo. (Grupo de Trabalho sobre o Processo de Reprodução da População, 1972, vol. 1, p. 135)

Ao lado da extrema complexidade em operar no marco de uma teoria da sociedade que articularia as estruturas econômicas e políticas ao comportamento psicossocial dos indivíduos, fica evidente, já na primeira reunião, a formação de uma identidade por negação. A crítica aos supostos ideológicos implícitos na relação entre desenvolvimento econômico e crescimento populacional e à associação entre a ofensiva antinatalista e a proliferação dos estudos de fecundidade na América Latina ganha posição central no programa de trabalho do GT. Porém, ainda que tenha havido consenso entre os participantes sobre a necessidade de encontrar novos marcos teóricos para o desenvolvimento dos estudos, o esforço envolvido nesta tarefa mostrava-se incapaz de acomodar, de fato, os diferentes pontos de vista e interesses de pesquisa.

Havia os que, concordando com a insuficiência teórica no campo, apostavam em análises empíricas mais criteriosas, sem a necessidade de redefinição do objeto de estudos. Tratava-se de desenvolver indicadores e modelos de análise que pudessem dar conta das tendências e diferenciais da 
fecundidade na região. Outros, porém, julgavam ser necessária e prioritária uma redefinição completa das questões de pesquisa, inserindo o comportamento da fecundidade em uma problemática mais ampla. É possível dizer que, apesar da crítica ideológica, permanece ao longo do tempo de vida do GT uma tensão entre uma demografia mais formal - e a preocupação com indicadores e modelos - e a discussão e formulação de novos marcos teóricos.

O prosseguimento das atividades do GT evidencia as dificuldades de uma dentre as tendências adquirir hegemonia. Pensamos que uma das razões que explicam a dificuldade do grupo para construir a sua identidade por afirmação, definindo claramente o objeto de pesquisa, decorria da forte resistência a estudar o tema da fecundidade, cujos resultados poderiam ser manipulados para políticas desse tipo. Além disso, o aparente consenso entre os que defendiam o estudo do processo de reprodução da população, numa perspectiva mais ampla, embutia objetos de pesquisa bastante distintos e supostos teóricos e metodológicos diversos. Podemos dizer que havia uma tensão ou conflito entre uma leitura teórica marxista de orientação mais estruturalista e outra, mais propensa a acomodar as determinações recíprocas das condições materiais e culturais. Ao longo das atividades do GT, porém, resultados de pesquisa foram discutidos ao lado de contribuições teóricas. Estes resultados ao mesmo tempo respondem a inquietações e interferem nas discussões que se processavam no âmbito do GT, abrindo questões e concretizando caminhos teórico-metodológicos.

Algumas contribuições do trabalho no e em torno do Grupo de Trabalho sobre o Processo de Reprodução da População do Clacso, importantes no pensamento crítico em demografia forjado na região, merecem ser resgatadas.

A primeira diz respeito à importância da dimensão sociocultural para a compreensão das condições em que comportamentos da fecundidade tomam forma. Ao contrário do que muitos críticos afirmam, a perspectiva histórico-estrutural na América Latina foi capaz de entender a complexidade do comportamento da fecundidade e suas múltiplas determinações. Construindo uma visão sofisticada da dinâmica social, a produção teórica e empírica colocou na agenda a questão das mediações entre os elementos de natureza material e o comportamento individual. Dentre estas mediações destacaram-se as instituições sociais de uma maneira geral e a família em particular. Os elementos da cultura, longe de permanecerem no limbo dos fatores ideológicos, dos valores, são entendidos como parte dos constrangimentos e possibilidades oferecidos em contextos históricos particulares, sujeitos à ação dos indivíduos.

Esta contribuição é tributária de outra que, em diferentes formas e matizes, aparece como ponto de vista teórico-metodológico a estabelecer a ponte entre abordagens distintas desenvolvidas na região. Trata-se da idéia de que os processos e fenômenos devem ser compreendidos no contexto no qual ocorrem, aí entendidas as circunstâncias de tempo e lugar. A análise contextual supõe que os fenômenos estudados têm significados distintos, a depender da diversidade das situações sociais concretas investigadas. A idéia de uma explicação e de um conhecimento necessariamente situados decorre da sólida formação teórica daqueles que estiveram engajados no projeto intelectual responsável pela constituição do campo da demografia na América Latina dos anos 70. Pode-se afirmar que esta é outra das acepções da noção de mediação tal como desenvolvida na região, já que diz respeito à articulação dialética entre uma hipótese (teórica) sobre o real e as condições e fatores encontrados na própria realidade empírica.

A família, como organização e como norma moral, foi, a partir dos trabalhos desenvolvidos em torno do GT do Clacso, recolocada na agenda demográfica. De um lado, advogou-se a relevância dos fenômenos e processos apreendidos no âmbito das famílias para a compreensão da dinâmica demográfica como um processo social. De outro, a família passou a ser um objeto legítimo de pesquisa demográfica, envolvendo um conjunto de questões 
relevantes em si mesmas e independentes de seu papel na explicação da fecundidade. É nessa dupla embocadura que ganhou terreno nos estudos demográficos a noção de estratégia de sobrevivência, de longe aquela que alcançou maior prestígio como síntese de uma aspiração de compreensão do que era entendido até então como comportamento.

Por fim, mas não menos importante, a demografia crítica no Brasil e na América Latina trouxe para suas formulações os paradigmas da sociologia, da antropologia e da economia política, em um clima que, se não permitiu um consenso afirmativo, foi responsável por um rico intercâmbio de pontos de vista e de experimentação. Apesar de muitos terem, à época, exorcizado metodologias qualitativas, estas se transformaram em recursos quase obrigatórios em algum momento da pesquisa demográfica não apenas na América Latina.

\section{Comentários finais}

A falta de uma identidade positiva clara pode ter sido uma das causas da dificuldade de sintetizar um conjunto de idéias inovadoras sobre os estudos de fecundidade. A insistência no significado da idéia "reprodução da população", mesmo reconhecendo que não se estudou a mortalidade e não se conseguiu a integração desejada com o estudo das migrações, trouxe, em nosso modo de ver, dificuldades não apenas na retórica da sedução de um auditório mais amplo mas, como conseqüência, também para a legitimação dos pequenos mas significativos avanços neste campo teórico e de pesquisa.

O sonho de uma ciência social unificada, com todas as suas matrizes disciplinares, não era exclusividade deste projeto intelectual. Pelo contrário, era uma posição dominante na América Latina da época, e era produto, por um lado, da forte tradição marxista - uma matriz de pensamento prédisciplinar e, portanto, totalizadora - e, por outro, produto da reação à hegemonia de um tipo de ciência social funcionalista, extremamente simplificadora, mecanicista e ahistórica nos estudos de população.
Para alguns, talvez, este esforço terá morrido na praia. Mais de uma vez ouvimos comentários em discussões acadêmicas no Brasil e no exterior que, se no calor dos anos 70 poderiam ser tomados como provocações políticas - como de fato tomamos -, hoje podemos neles nos deter estimulados por instigante provocação intelectual. O texto é mais ou menos o seguinte: a queda relativamente recente da fecundidade nos países em desenvolvimento - por seu ritmo acelerado e generalidade em diferentes segmentos e regiões - teria sepultado de vez a chamada abordagem históricoestrutural. Esta abordagem não foi capaz de detectar - e muito menos explicar - a queda extremamente acentuada já em curso na América Latina à época em que formulávamos e construíamos tal abordagem. Zero a zero seria o resultado do placar do embate de paradigmas, pois se a teoria da modernização não era capaz de dar conta da experiência histórica dos países que chegaram depois na corrida pela riqueza mundial, a formulação alternativa não mostrou a que veio. O caráter fortemente político dos idos dos anos 70 teria impedido que pudéssemos admitir a existência de uma demanda real e crescente por anticoncepção, no Brasil e em outros países da região.

Não pretendemos nos estender muito mais nesta recuperação do passado. Mas queríamos chamar a atenção para o fato de que, apesar do prestígio de teorias de difusão, está cada vez mais evidente na produção de autores com maior estofo intelectual no cenário internacional que a mudança cultural não ocorre em um vazio estrutural. Ou seria razoável sustentar que o Brasil e a América Latina não mudaram nos 30 anos que nos separam da década de 70 ? Também não podemos esquecer que as metodologias de análise de dados e a própria produção de informações sobre a fecundidade sofreram importantes mudanças nas últimas décadas. Análises contextuais e de vários níveis são cada vez mais requeridas e utilizadas em estudos que escapam à mesmice de modelos de regressão. Na Europa e nos Estados Unidos, as hipóteses mais interessantes acerca da 
fecundidade abaixo do nível de reposição populacional lançam mão de argumentos estruturais e - o que é extremamente interessante - incorporam uma noção analítica de gênero, entendida como categoria teórica estruturante das relações sociais.

Olhando da perspectiva temporal que aqui adotamos e numa mirada desde a província, não podemos deixar de pensar que o esforço dos anos 70 não foi em vão. Obviamente não teríamos a pretensão de pensar que determinados avanços apontados acima no âmbito internacional sejam tributários de uma produção latino-americana. Mas não podemos deixar de lembrar que as relações Norte-Sul se incrementaram muito dos anos 70 para cá, e que muitos especialistas em população - na academia e nas agências - tiveram sim contato com a produção da América Latina, embora esta não tenha sido submetida sistematicamente ao escrutínio internacional, pois que publicada em espanhol ou em português. A dificuldade lingüística, mas também algum etnocentrismo, impediu um debate mais significativo entre o Norte e o Sul.

Olhando para o futuro, o tema da intensificação do intercâmbio e da cooperação na América Latina e no Caribe nos remete para a necessidade de superar o paroquialismo que ainda pode nos abater. Seja aquele que nos previne com relação a influências de fora, seja o paroquialismo

\section{Referências bibliográficas}

ALDUNATE, A. Análisis de la práctica de investigación en el campo específico de los estudios de fecundidad. In: CLACSO, Reproducción de la población y desarrollo. Montevidéu: Clacso, vol. 1, 1978.

Algunas reflexiones en torno a las relaciones entre industrialización y reproducción de la población. In: CLACSO, Reproducción de la población y desarrollo. Montevidéu: Clacso, vol. 2, 1982a.

Estudos de unidades familiares a partir das pesquisas comparativas de fecundidade. In: CLACSO, Reproducción de la población y desarrollo. Montevidéu: Clacso, vol. 2, 1982b. que nos impede de valorizar o que temos a oferecer, porque o bom estaria lá, no Norte. Cremos que as relações Norte-Sul são hoje certamente mais complexas, multifacetadas e amplas do que eram nos idos de 70 . Cremos também que a prática da pesquisa em grupo, via projetos de maior porte, nos permite superar o impasse que vivemos décadas atrás, qual seja, o da insuficiência de formação e/ou de habilidades em técnicas quantitativas relativamente sofisticadas por parte dos mais críticos teoricamente e, ao mesmo tempo, a insuficiência de formação e/ou de habilidades em teoria social por parte dos mais afeitos à quantificação. Não temos dúvidas de que a intensificação da cooperação latino-americana deverá envolver esforços interinstitucionais de pesquisa, mediante uma variedade de modelos e mecanismos. $E$, quem sabe, a pesquisa em equipes e a maior disponibilidade de dados permitirão construir os trens de pouso na realidade dos fatos da mudança demográfica.

Os desafios da demografia na América Latina e no Caribe são muitos e requerem um esforço coletivo que não será pequeno. Em especial, os mecanismos de financiamento à pesquisa estão na agenda das questões difíceis a enfrentar. E sabemos das dificuldades. Mas, já passamos por outras e saberemos encontrar os caminhos que nos levarão a resultados e a avanços.

Reproducción de la población en 10 ciudades de América Latina (un ensayo de interpretación sociológica). In: CLACSO, Reproducción de la población y desarrollo. Montevidéu: Clacso, vol. 2, 1982c.

BENITEZ, R. e QUILODRAN, J. Análisis de la nupcialidad através de la Historia de Uniones. In: La fecundidad en México. Cidade do México: El Colegio de MexicoUnam, 1983.

BERQUÓ, E. Algumas indagações sobre a recente queda da fecundidade no Brasil. In: CLACSO, Reproducción de la población y desarrollo. Montevidéu: Clacso, vol. 4, 1983a. 
BERQUÓ, E. Pesquisa sobre reprodução humana no Brasil. In: CLACSO, Reproducción de la población y desarrollo. Montevidéu: Clacso, vol. 4, 1983b.

BERQUÓ, E. e FARIA, V. Migrações e fecundidade em quatro contextos brasileiros. In: CLACSO, Reproducción de la población y desarrollo. Montevidéu: Clacso, vol. 5, 1985.

CONNING, A. Encuestas comparativas de fecundidad en América Latina: algunos aspectos metodológicos. REUNIÃO DA SBPC, 24, São Paulo, 1972. Anais... São Paulo: SBPC, 1972.

FARIA, V. Organização da produção e dinâmica populacional. In: CLACSO, Reproducción de la población y desarrollo. Montevidéu: Clacso, vol. 2, 1982.

GAMA, I.O.G. Prelúdio del descenso de la fecundidad en México. In: CLACSO, Reproducción de la población y desarrollo. Montevidéu: Clacso, vol. 5, 1985.

GARCIA, B. e FIGUEIROA, B. Encuestas de fecundidad en América Latina. In: CLACSO, Reproducción de la población y desarrollo. Montevidéu: Clacso, vol. 1, 1978.

GARCIA, B., MUÑOZ, H. e OLIVEIRA, O. Los trabajadores y sus unidades domésticas en la Ciudad de México. In: CLACSO, Reproducción de la población y desarrollo. Montevidéu: Clacso, vol. 4, 1983.

Población y estructura familiar en dos contextos brasileños. In: CLACSO, Reproducción de la población y desarrollo. Montevidéu: Clacso, vol. 5, 1985.

GRUPO DE TRABAJO sobre el Proceso de Reproducción de la Población de la Comisión de Población e Desarrollo del Consejo Latinoamericano de Ciencias Sociales. Informe de la primera reunión, vol. 1, 1972.

LAMOUNIER, B. Industrialización, inmigración y comportamiento reproductivo (notas para un modelo en situación de cambio). In: CLACSO, Reproducción de la población y desarrollo. Montevidéu: Clacso, vol. 2, 1982.
LERNER, S. e QUESNEL, A. La estructura familiar como expresión de condiciones de reproducción social y demográfica. El caso de la Zona Henequera en Yucatán. In: CLACSO, Reproducción de la población y desarrollo. Montevidéu: Clacso, vol. 5, 1985.

LOYOLA, M.A. Introdução ao estudo das instituições sociais e o comportamento reprodutivo em Parnaíba: as instituições religiosas, a unidade de produção econômica e a família. Estudos de População, São Paulo, Cebrap, n. 3, 1978.

MARTIN, M.S. Habitus de classe e estratégias de reprodução. In: CLACSO, Reproducción de la población y desarrollo. Montevidéu: Clacso, vol. 4, 1983.

MIRÓ, C.A. Las tendencias recientes de le fecundidad en América Latina y sus implicaciones. In: CLACSO, Reproducción de la población y desarrollo. Montevidéu: Clacso, vol. 5, 1985.

MONTALLI, L. e PATARRA, N.L. Estudo da reprodução: anotações críticas sobre sua evolução e encaminhamento de propostas alternativas. In: CLACSO, Reproducción de la población y desarrollo. Montevidéu: Clacso, vol. 2, 1982.

MUNDIGO, A. e LANDSTREET, B. Determinantes del cambio de la fecundidad en Cuba - políticas y tendencias recientes. In: CLACSO, Reproducción de la población y desarrollo. Montevidéu: Clacso, vol. 5, 1985.

OLIVEIRA, M.C. Notas sobre a união dos sexos e família: tipos e fundamentos da legitimidade. In: CLACSO, Reproducción de la población y desarrollo. Montevidéu: Clacso, vol. 2, 1982.

Notas acerca da família nos estudos demográficos. In: CLACSO, Reproducción de la poblacion y desarrollo. Montevidéu: Clacso, vol. 5, 1985.

PAIVA, P.T.A. O processo de proletarização como fator de desestabilização dos níveis de fecundidade no Brasil. In: CLACSO, Reproducción de la población y desarrollo. Montevidéu: Clacso, vol. 5, 1985. 
PATARRA, N. e OLIVEIRA, M.C. Anotaciones criticas sobre los estudios de fecundidad. In: CLACSO, Reproducción de la población y desarrollo. Montevidéu: Clacso, vol. 1, 1978.

RODRIGUES, A. Revisão crítica do tipo de explicações sobre o comportamento reprodutivo nas pesquisas de fecundidade e proposta de um modelo alternativo. In: CLACSO, Reproducción de la población y desarrollo. Montevidéu: Clacso, v. 2, 1982.

Algumas contribuições para a pesquisa sobre o comportamento humano. In: CLACSO, Reproducción de la población y desarrollo. Montevidéu: Clacso, vol. 4, 1983a.

Dinâmica grupal e indivíduo no sistema de distribuição de privilégios na família. In: CLACSO, Reproducción de la población y desarrollo. Montevidéu: Clacso, vol. 4, 1983b.

TAVARES, R.A.W. Reprodução da população e desenvolvimento. Micro-história do pensamento de um grupo de trabalho. Tese de doutorado em Ciências Sociais. Campinas: Universidade Estadual de Campinas, 2001.

WEISS-ALTANER, E. Economía clásica, familia y actividad femenina. Demografía y
Economía, Colegio do México, vol. 11, n. 33, 1977.

Aspectos económicos de una teoría de la fecundidad. In: CLACSO, Reproducción de la población y desarrollo. Montevidéu: Clacso, vol. 2, 1982.

WELTI C.,C. Algunas consideraciones teóricas para el estudio de la población en América Latina. In: CLACSO, Reproducción de la población y desarrollo. Montevidéu: Clacso, vol. 2, 1982.

Algunos factores asociados al descenso de la fecundidad, analizados a partir de la información de la encuesta mexicana de fecundidad de 1976. In: CLACSO, Reproducción de la población y desarrollo. Montevidéu: Clacso, vol. 5, 1985.

WOOD, C.H. e CARVALHO, J.A. Crescimento populacional e distribuição de renda familiar: o caso brasileiro. In: CLACSO, Reproducción de la población y desarrollo. Montevidéu: Clacso, vol. 4, 1983.

ZENTENO, R. Sobrepoblación, subdesarrollo y política de población en México. In: CLACSO, Reproducción de la población y desarrollo. Montevidéu: Clacso, vol. 2, 1982.

\begin{abstract}
Records and memory: observations on Brazilian demography in the Latin-American context

This article consists of a discussion, after an interval of 30 years, on the meaning of the turbulent 1970s in Brazilian and Latin-American demography. The authors use an approach that includes both self-criticism and celebration, bringing together written material and recollections about a phenomenon that, at that time, was a collective, scientific and political project in the region. The article thus deals with the social, political and economic context of the period, the characteristics of leading demographers of the time, the style of international funding for groups and institutions, and the critical character of scientific practice in demography during that period. In a critical appraisal of the intellectual history of a group, the authors recognize that the process under discussion allows for varying points of view and considerations. Bibliographic references are included in order to document some extant records and provide an agenda for those who may also want to study the same period.
\end{abstract}

Key words: Brazilian demography. Demography in Latin America. Fertility studies. History of demography. 